https://helda.helsinki.fi

Balloon catheter use for cervical ripening in women with term pre-labor rupture of membranes : A 5-year cohort study

Kruit, Heidi

2020-09

Kruit , H , Tolvanen , J , Eriksson , J , Place , K , Nupponen , I \& Rahkonen , L 2020 , '

Balloon catheter use for cervical ripening in women with term pre-labor rupture of membranes : A 5-year cohort study ', Acta Obstetricia et Gynecologica Scandinavica, vol. 99 , no. 9 , pp. 1174-1180 . https://doi.org/10.1111/aogs.13856

http://hdl.handle.net/10138/328677

https://doi.org/10.1111/aogs.13856

acceptedVersion

Downloaded from Helda, University of Helsinki institutional repository.

This is an electronic reprint of the original article.

This reprint may differ from the original in pagination and typographic detail.

Please cite the original version. 
DR HEIDI KRUIT (Orcid ID : 0000-0003-0350-7088)

DR LEENA RAHKONEN (Orcid ID : 0000-0003-4507-6917)

Article type : Original Research Article

\section{Balloon catheter use for cervical ripening in women with term pre-labor rupture of membranes; a five-year cohort study}

Heidi Kruit ${ }^{1}$, Jenna Tolvanen ${ }^{2}$, Jasmin Eriksson ${ }^{2}$, Katariina Place ${ }^{1}$, Irmeli Nupponen ${ }^{3}$, Leena Rahkonen ${ }^{1}$

${ }^{1}$ Department of Obstetrics and Gynecology, University of Helsinki and Helsinki University Hospital, Helsinki, Finland

${ }^{2}$ Faculty of Medicine, University of Helsinki, Helsinki, Finland

${ }^{3}$ Department of Neonatology, University of Helsinki and Helsinki University Hospital, Helsinki, Finland

\section{Correspondence:}

Heidi Kruit

Helsinki University Hospital, Department of Obstetrics and Gynecology, Haartmaninkatu 2, 00029 HUS, Finland

E-mail: heidi.kruit@hus.fi

This article has been accepted for publication and undergone full peer review but has not been through the copyediting, typesetting, pagination and proofreading process, which may lead to differences between this version and the Version of Record. Please cite this article as doi: $\underline{10.1111 / \text { AOGS. } 13856}$

This article is protected by copyright. All rights reserved 


\section{Conflict of interest}

None

\section{ABSTRACT}

Introduction: To investigate safety of balloon catheter for cervical ripening in women with term pre-labor rupture of membranes (PROM), and to compare the incidence of maternal and neonatal infections in women with PROM and women with intact membranes undergoing cervical ripening with a balloon catheter. Material and methods: This retrospective cohort study of 1923 women with term singleton pregnancy and an unfavorable cervix undergoing cervical ripening with a balloon catheter was conducted in Helsinki University Hospital between January 2014 and December 2018. For each case of PROM, two controls were assigned. The main outcome measures were the rates of maternal and neonatal infections. Statistical analyses were performed by SPSS. Results: 641 (33.3\%) women underwent labor induction following PROM and 1282 $(66.6 \%)$ women with intact amniotic membranes. The rates of intrapartum infection $(3.7 \% \mathrm{vs}$. $7.7 \% ; \mathrm{p}=0.001)$ and neonatal infection $(1.7 \%$ vs. $3.8 \% ; \mathrm{p}=0.01)$ were not increased in women induced by balloon catheter following PROM. Intrapartum infections were associated with nulliparity (OR 3.3, 95\% CI 1.6-6.5), history of previous cesarean section (OR 2.8, 95\% CI 1.26.4), extended gestational age $\geq 41$ weeks (OR 1.9, 95\% CI 1.2-3.0) and induction to delivery 
interval of $48 \mathrm{~h}$ or more (OR 2.0, 95\% CI 1.2-3.3). The risk of neonatal infection was associated with nulliparity (OR 3.3, 95\% CI 1.4-8.0), gestational age $\geq 41$ weeks (OR 1.9, 95\% CI 1.09-3.36) and induction to delivery interval of $48 \mathrm{~h}$ or more (OR 3.4, 95\% CI 1.9-6.0). Conclusions: Use of balloon catheter in women with term PROM appears safe and was not associated with increased maternal or neonatal infectious morbidity.

\section{Keywords}

Term pre-labor rupture of membranes

Induction of labor

Cervical ripening

Balloon catheter

Intrapartum infection

Neonatal infection

\section{Abbreviations}

PROM; pre-labor rupture of membranes

IOL; induction of labor

$\mathrm{BC}$; balloon catheter

RCT; randomized controlled trial

GBS; Group B Streptococcus

\section{Key message}

Cervical ripening by a balloon catheter in women with term pre-labor rupture of membranes appears safe, and was not associated with increased infectious morbidity in a five year cohort study. 


\section{INTRODUCTION}

Pre-labor rupture of membranes (PROM), defined as rupture of membranes at least one hour prior to onset of regular contractions, occurs in approximately $8 \%$ of term pregnancies. Sixty percent of the women with PROM deliver spontaneously within 24 hours (1). Prolongation of onset of labor for more than 24 hours is associated with an increased incidence of chorioamnionitis and neonatal sepsis $(1,2)$. There are multiple management guidelines for PROM, including expectant management and immediate induction of labor (IOL) with oxytocin or prostaglandins $(1,3-5)$. The recent Cochrane review supports IOL within 24 hours from PROM for lower risk of maternal and neonatal infections without an increase in the rate of cesarean section (6).

An abundance of studies support the efficacy of balloon catheter (BC) for cervical ripening considering the low risk of uterine hyperstimulation, fetal heart rate abnormalities, and adverse maternal outcomes after previous cesarean section (7,8-10). However, most studies include only women with intact amniotic membranes, while the use of BC in women with ruptured amniotic membranes has raised concerns over infectious morbidity. Only a few small studies with limited data exist on the safety of the use of BC in women with PROM. Reassuring results on the use of $\mathrm{BC}$ following term PROM have been reported by two relatively small retrospective cohort studies $(11,12)$, a randomized controlled trial (RCT) of 188 women comparing BC and oral misoprostol for cervical ripening following term PROM (13) and a RCT comparing concurrent use of BC and oxytocin with oxytocin only in 128 women (14). On the contrary, another RCT comparing concurrent $\mathrm{BC}$ and oxytocin use with oxytocin only in 201 preterm or term women reported increased rates of chorioamnionitis following the use of $\mathrm{BC}$, although infections were associated with longer induction-to-delivery interval (15).

The aim of this five-year cohort study was to assess the safety of use of $\mathrm{BC}$ for cervical ripening following PROM, and to compare the incidence of maternal and neonatal infections in women with PROM and women with intact amniotic membranes undergoing cervical ripening with $\mathrm{BC}$.

\section{MATERIAL AND METHODS}

This cohort study of women $\geq 37$ gestational weeks undergoing IOL and cervical ripening by BC between January 2014 and December 2018 was conducted in the Department of Obstetrics and 
Gynecology in Helsinki University Hospital, with approximately 13500 deliveries annually. All women with PROM, vital singleton pregnancy in cephalic presentation at $\geq 37$ weeks of gestation, and an unfavorable cervix (Bishop score $(16)<6$ ) were included in the study. For each case of PROM, two controls of women undergoing cervical ripening by $\mathrm{BC}$ for any reason other than PROM were assigned. The controls were selected from the hospital database by including the one woman who had undergone cervical ripening by $\mathrm{BC}$ and given birth prior to the case, and the one who had undergone cervical ripening by $\mathrm{BC}$ and given birth following the case.

PROM was diagnosed by clinical examination combined with a positive rapid vaginal insulin-like growth factor binding protein-1 dipstick test (ActimProm ${ }^{\circledR}$, Medix Biochemica, Espoo, Finland). A single 40-80 ml BC (Rüsch 2 way Foley Couvelaire tip catheter size $22 \mathrm{Ch}$, Teleflex Medical, Athlone, Ireland) was used for cervical ripening in all women. According to the hospital management guidelines, the balloon was retained for a maximum of 8 hours in case of PROM, and 24 hours in women with intact amniotic membranes. If the cervix remained unripe with Bishop score $<6$ after $\mathrm{BC}$ expulsion or removal, induction was continued at the discretion of the treating obstetrician. If Bishop score $\geq 6$ was reached, IOL was continued by amniotomy in case of intact amniotic membranes, and oxytocin in the absence of spontaneous contractions. Oxytocin augmentation and continuous cardiotocography during labor were routinely used.

Group B Streptococcus (GBS) was tested in all women by a rapid qualitative in vitro GBS test (Xpert ${ }^{\circledR}$ GBS; Cepheid, Sunnyvale, CA, USA) at the time of admission. Administration of prophylactic antibiotics was started to all GBS-positive women at the time of rupture of membranes or at the time of diagnosing PROM. Benzylpenicillin was routinely used for antibiotic prophylaxis with the first dose of $2.4 \mathrm{~g}$ intravenously, followed by $1.5 \mathrm{~g}$ every 4 hours until delivery. In case of a penicillin allergy, clindamycin $900 \mathrm{mg}$ or cefuroxime $1.5 \mathrm{~g}$ were administered every 8 hours intravenously. Additionally, according to the hospital policy, all women with ruptured membranes received one dose of prophylactic antibiotics during BC retention, regardless of the GBS-result.

The primary outcomes were the rates of maternal and neonatal infections. Maternal infections were categorized as intrapartum (during labor) and postpartum (within one week from delivery). The criteria for intrapartum infection were maternal fever $\geq 38^{\circ} \mathrm{C}$ during labor and at least one of the following: fetal tachycardia $\geq 160 \mathrm{bpm}$, uterine tenderness, purulent amniotic fluid or vaginal 
discharge, total white cell count $>15 \mathrm{E} 9 / \mathrm{L}$. Postpartum infections included endometritis, cesarean or episiotomy wound infection, sepsis, and puerperal fever of unknown origin. Neonatal infections were categorized into blood culture positive sepsis, clinical sepsis, suspected sepsis, and other suspected infection by a neonatologist. Neonatal clinical sepsis was defined as blood culture negative infection with symptoms and signs consistent with sepsis (respiratory distress, apnea, tachycardia, poor perfusion, low blood pressure, fever, hypoglycemia or hyperglycemia, irritability, feeding problems, lethargy, convulsions) and abnormal blood values (C-reactive protein (>20 mg/l), leukocytosis or leucopenia, increased neutrophil precursors and thrombocytopenia). The cases of suspected sepsis had at least one symptom and at least one abnormal laboratory test value (as listed with clinical sepsis), and a positive response to antibiotic treatment.

The secondary outcomes were the mode of delivery, postpartum hemorrhage, Apgar score, umbilical artery blood gas values, admission to neonatal care, and induction to delivery interval.

The data on baseline characteristics and delivery outcomes were obtained from the hospital database. Late-term pregnancy was defined as gestational age $41^{+0}-41^{+6}$ weeks and post-term pregnancy was defined as gestational age $\geq 42$ weeks. Gestational diabetes was diagnosed by at least one pathological value in 2-hour oral glucose tolerance test. The $\mathrm{BC}$ retention time was defined as an interval from balloon insertion to spontaneous expulsion or removal. The induction to delivery interval was defined as the time from insertion of the $\mathrm{BC}$ to delivery. Failed induction was diagnosed after ruptured membranes and 12 hours of oxytocin administration without cervical change (17). Duration of labor was defined as the time from the start of regular contractions with cervical dilation of $6 \mathrm{~cm}$ to delivery.

Statistical analyses were performed by using IBM SPSS Statistics for Windows, Version 26.0 (IBM Corp., Armonk, NY, USA). Categorical variables were analyzed for odds ratios (OR) with 95\% confidence interval (CI). Categorical variables were compared by the chi-square test and Fisher's exact test when appropriate. Data with continuous variables were performed by T-test when the data followed normal distribution and by a Mann-Whitney $U$ test if the data did not follow normal distribution. Univariate and multivariate logistic regression analyses were performed to assess relative risk for intrapartum infection. Variables used in the multivariate analyses were parity, maternal age, height, IOL indication, in-vitro fertilization, smoking, body 
mass index, previous cesarean section, Bishop score, gestational age, gestational diabetes, need of oxytocin induction, epidural/spinal analgesia, and the induction to delivery interval $\geq 48 \mathrm{~h}$.

Adjusted OR with 95\% CI were calculated by modelling the data to control for possible confounding factors. A p-value $<0.05$ was considered statistically significant.

\section{Ethical approval}

The study was approved by the Institutional Review Board of the hospital region (Helsinki and Uusimaa Hospital District Committee for Obstetrics and Gynecology), (nr. HUS/3172/2018, HUS/54/2019 and HUS/6/2015). Due to the retrospective nature of the study, written informed consent was waived by the Institutional Review Board according to national legislation (Medical Research Act 488/1999, chapter 2 a (23.4.2004/295), section 5 and 10a).

\section{RESULTS}

A total of 1923 women were included in the study. Of these, 641 (33.3\%) underwent labor induction and cervical ripening by BC following PROM and 1282 (66.6\%) with intact amniotic membranes. The characteristics of the study population are presented in Table 1 . The mean age of the women was 31.5 (5.3 SD) years, the mean body mass index $25.4(5.4 \mathrm{SD})$ and the mean gestational age 40.4 (1.4 SD) weeks. The women induced for reasons other than PROM were more obese, more often were smokers, and more often had gestational diabetes and late-term or post-term pregnancy (Table 1). The most common indications for labor induction in the nonPROM group were post-date pregnancy (41\%), gestational diabetes (12.9\%), hypertensive disorders $(11.0 \%)$, maternal request for psychosocial reasons $(8.0 \%)$, intrahepatic cholestasis of pregnancy $(7.2 \%)$, oligohydramnios $(5.1 \%)$ and intrauterine growth restriction $(4.7 \%)$.

Table 2 presents the delivery outcomes. The median time from PROM to start of IOL was $27.3 \mathrm{~h}$ (range $1.7-328 \mathrm{~h}$ ). The median $\mathrm{BC}$ retention time was 4.0 (range $0.1-18.0$ ) $\mathrm{h}$ in women with PROM and 6.4 (range $0.1-28.5) \mathrm{h}$ in women with intact amniotic membranes $(\mathrm{p}<0.001)$. There were no significant difference in the rates of cesarean section between the groups ( $23.7 \mathrm{vs.} 23.7 \%$; $\mathrm{p}=0.82$ ) (Table 2). Induction to delivery interval was longer in women with intact amniotic membranes (26.2 [3.1-164] h vs. 17.4 [2.6 - 75.7] h; $p<0.001)$, but the duration of labor was longer in women with PROM (6.7 [0.4 - 31.3] h vs. $7.7[0.9-36.5] \mathrm{h} ; \mathrm{p}<0.001)$ (Table 2). The 
rates of low Apgar scores and low umbilical artery $\mathrm{pH}$-values did not differ between the groups, but there were more admissions to NICU among the women with intact amniotic membranes (Table 2).

The total rate of intrapartum infection was $6.4 \%(n=123)$. The rate of intrapartum infection was lower in women induced for PROM compared to women induced with intact amniotic membranes (3.7 \% vs. $7.7 \%$; $p=0.001$, OR 0.5, 95\% CI 0.3-0.7) (Table 3). After adjustment with cofounding factors, intrapartum infections were associated with nulliparity (OR 3.3, 95\% CI 1.6-6.5; $\mathrm{p}=001$ ), history of previous cesarean section (OR 2.8, 95\% CI 1.2-6.4; $\mathrm{p}=0.02)$, extended gestational age $\geq$ 41 weeks (OR 1.9, 95\% CI 1.2-3.0; $\mathrm{p}=0.003$ ) and induction to delivery interval of $48 \mathrm{~h}$ or more (OR 2.0, 95\% CI 1.2-3.3; $\mathrm{p}=0.005$ ) (Table 4A).

The total rate of postpartum infections was $2.5 \%(\mathrm{n}=49)$, and the rates of postpartum infections were similar between the women induced for PROM and the women induced for reasons other than PROM (2.0 \% vs. $2.8 \%$; 0.31) (Table 3$)$. Eight cases $(0.5 \%)$ of blood culture positive septicemia occurred, two in the PROM group and six in the women with intact amniotic membranes (Table 3). Two of these occurred during labor and six occurred postpartum.

The total rate of neonatal infections was $3.1 \%(n=60)$, being $1.7 \%$ among the women with PROM and $3.8 \%$ among the women with intact membranes $(\mathrm{p}=0.01)$. One case of neonatal blood culture positive (Staphylococcus Aureus) sepsis occurred in the non-PROM group following vaginal delivery and no maternal infection. After adjustment, the risk factors for neonatal infection were nulliparity (OR 3.3, 95\% CI 1.4-8.0; $\mathrm{p}=0.01$ ), gestational age $\geq 41$ weeks (OR 1.9, 95\% CI $1.09-3.36 ; \mathrm{p}=0.03$ ) and induction to delivery interval of $48 \mathrm{~h}$ or more (OR 3.4, 95\% CI 1.9-6.0; $\mathrm{p}<0.001$ ) (Table 4B). When including only neonatal blood culture positive or clinical sepsis, the induction to delivery interval $>48$ hours remained significant, OR 12.6 (95\% CI $3.5-45.2)$; $\mathrm{p}<0.001$.

\section{DISCUSSION}

Our results suggest that use of $\mathrm{BC}$ for cervical ripening following PROM is safe and did not increase the incidence of maternal or neonatal infections compared to women undergoing IOL and $\mathrm{BC}$ cervical ripening with intact amniotic membranes. On the contrary, the rates of maternal 
intrapartum and neonatal infections were higher in the women who underwent BC cervical ripening with intact amniotic membranes. However, this may be partly explained by the prophylactic antibiotic use during BC retention in the PROM group, and by the fact the women with intact membranes more often had risk factors such as obesity, smoking, gestational diabetics, and extended gestational age. The women without PROM also had longer induction to delivery intervals, which is known to be associated with increased rates of maternal and neonatal infection. PROM may represent early onset of labor, and therefore more appropriate comparison group may have been women with PROM who underwent cervical ripening by methods other than $\mathrm{BC}$. We acknowledge another major limitation of the study being the prophylactic antibiotic use. In our study, prophylactic antibiotics were routinely administered during $\mathrm{BC}$ retention according to the hospital management policy. The authors are aware that the use of prophylactic antibiotics during $\mathrm{BC}$ retention in case of ruptured membranes is controversial and question this policy. On the contrary, the women who received antibiotic had significantly lower rates of infections. Following these encouraging results, we are currently reevaluating the antibiotic regimen policy in our hospital. Another major weakness of the study is the lack of histopathological diagnosis of chorioamnionitis for all women with suspected chorioamnionitis. However, this is so far the largest cohort study on the safety of the use of BC in women with ruptured membranes, and adds to the limited data available. As large proportion of IOL is carried out due to PROM, and an increasing number of women have a history of previous caesarean section, it is important to assess the safety and feasibility on the use of $\mathrm{BC}$ in cases of ruptured membranes.

The duration of $\mathrm{BC}$ retention in both groups deviated from the hospital guidelines of eight hours in case of ruptured membranes and 24 hours in case of intact membranes. However, the duration of $\mathrm{BC}$ retention was not associated with the maternal or neonatal infections. Our results suggest that the $\mathrm{BC}$ can safely remain in the cervical canal for at least 8 hours following PROM, when prophylactic antibiotics are used during BC retention. In contrast, a previous study reported an increase in cervical pathogenic microbes, such as GBS, Candida albicans and Candida glabrata, and Gardnerella vaginalis during BC retention (18). In previous studies, $\mathrm{BC}$ retention time of $12-$ 24 hours is frequently described $(19,20)$, although a Dutch study used a maximum of 96 hours with $\mathrm{BC}$ replacement every $24-48$ hours, with no increase in the rates of maternal and neonatal infectious morbidity (21). However, these studies have not detailed whether women with PROM 
were included in the management protocol. Furthermore, only few trials were explicit about the inclusion and management GBS-colonized women.

The rates of maternal intrapartum infections and postpartum infections in our study are consistent with the previously shown $7 \%$ rate of chorioamnionitis, and the $3.5 \%$ rate of postpartum endometritis following labor induction (22,23). Similar reassuring results on the use of BC following PROM at term have previously been reported by a small Swedish pilot study $(\mathrm{n}=18)$ (24), an American retrospective cohort study $(\mathrm{n}=122)(11)$ and by a Finnish randomized multicenter trial $(\mathrm{n}=188)(13)$ that recorded no increase in infections following BC use compared to oral misoprostol. Another retrospective study showed a trend towards a higher rate of chorioamnionitis in 43 women undergoing IOL by BC following PROM, compared with intravaginal misoprostol or intravenous oxytocin use (12). However, after adjustment, the increase was due to nulliparity and intrauterine pressure catheter use (12). Also in our study, nulliparity was associated with an increased risk for intrapartum infections. Increased risk of chorioamnionitis has been demonstrated in nulliparous women remaining in the latent phase for more than $12-15$ hours $(25,26$,$) , as also seen in our study, in which maternal and neonatal$ infections were associated with prolonged induction to delivery interval of $\geq 48$ hours. Interestingly, duration of PROM or GBS colonization were not associated with an increased risk for maternal or neonatal infections. In our clinic, GBS colonized women are induced the latest in $12 \mathrm{~h}$ following PROM, while the GBS-negative women are managed expectantly for $24 \mathrm{~h}$.

The $1.7 \%$ rate of neonatal infections following IOL in women with PROM was in line with the results of previous studies $(22,27)$. However, among the women induced for reasons other than PROM, the rate of neonatal infections was more than doubled. This may be partially explained by the longer induction to delivery interval and the higher rate of maternal intrapartum infections in the non-PROM group, as well as the antibiotic prophylaxis protocol which may have led to a reduced rate of infections in the PROM group. One case of blood culture positive neonatal sepsis occurred, which parallels the previously reported global sepsis incidence of approximately 1 per 1000 live births $(28,29)$. There were more NICU admissions in the women induced for reasons other than PROM, which may have resulted from the higher neonatal infections rate as well as the pregnancy complications that led to labor induction, such as post-term pregnancy, gestational diabetes, hypertensive disorders and intrauterine growth restriction. 
A randomized trial comparing 62 women with concurrent use of $\mathrm{BC}$ and oxytocin infusion to 66 women with oxytocin infusion alone reported a $10 \%$ rate of chorioamnionitis following the use of $\mathrm{BC}$, although this was not statistically significantly higher compared to the $5 \%$ rate of chorioamnionitis ion the oxytocin only group (15). Another RCT compared 93 women with concurrent use of $\mathrm{BC}$ and oxytocin to 108 women with oxytocin induction alone. They recorded 7 $\%$ chorionamnionitis rate on the BS group compared to $0 \%$ in the oxytocin group $(p<0.01)(14)$. Those with suspected intra-amniotic infection had a 9-hour longer induction to delivery interval than those without suspected infection (14). In this study BC was retained for 12 hours and the use of fetal scalp electrode was significantly more frequent in the BC group, although in their regression model it was not considered significant (14). However, these studies included also cases of preterm premature rupture of membranes, while the current study focused on women with term PROM. Additionally, the two previous studies included oxytocin use in women with unripe cervices, while our study concentrated on cervical ripening with $\mathrm{BC}$ and oxytocin was only started when Bishop score of six or more was reached. Contrarily, the Cochrane review suggests similar labor outcomes in women with PROM and an unfavourable cervices when comparing use of oxytocin and prior cervical ripening by prostaglandins (6). In our previous study, BC and misoprostol were as effective in labor induction following prolonged PROM (13). Thus, one may speculate is the use of BC an unnecessary intervention following PROM, and would oxytocin induction without prior cervical ripening be as effectively. Further studies are needed to substantiate the benefits of use of $\mathrm{BC}$ in women with prolonged PROM.

\section{CONCLUSION}

Our results suggest that with regards to maternal and neonatal infectious morbidity, BC appears a safe method for cervical ripening in women with ruptured membranes when prophylactic antibiotics are used. Intrapartum and neonatal infections in our study were associated with nulliparity, history of previous cesarean section, gestational age of $\geq 41$ weeks, and prolonged induction to delivery interval of 48 hours or more. Further investigations, ideally a randomized trial, are needed to substantiate these findings.

This article is protected by copyright. All rights reserved 


\section{Acknowledgments}

We thank Dr. Saara Mertsalmi, University of Helsinki for her assistance with the data.

\section{REFERENCES}

(1) Hannah ME, Ohlsson A, Farine D, et al. Induction of labor compared with expectant management for prelabor rupture of the membranes at term. TERMPROM Study Group. N Engl J Med 1996; 334(16):1005-1010.

(2) Gunn GC, Mishell DR,Jr, Morton DG. Premature rupture of the fetal membranes. A review. Am J Obstet Gynecol 1970; 106(3):469-483.

(3) Abraham C, Meirowitz N, Kohn N. Labor induction for premature rupture of membranes using vaginal misoprostol versus dinoprostone vaginal insert. Am J Perinatol 2014; 31(3):181-186.

(4) Radoff KA. Orally administered misoprostol for induction of labor with prelabor rupture of membranes at term. J Midwifery Womens Health 2014; 59(3):254-263.

(5) ACOG Committee on Practice Bulletins-Obstetrics. Practice bulletins No. 139: premature rupture of membranes. Obstet Gynecol 2013; 122(4):918-930.

(6) Middleton P, Shepherd E, Flenady V, McBain RD, Crowther CA. Planned early birth versus expectant management (waiting) for prelabour rupture of membranes at term (37 weeks or more). Cochrane Database Syst Rev 2017; 1:CD005302.

(7) Jozwiak M, Oude Rengerink K, Benthem M, van Beek E, Dijksterhuis MG, de Graaf IM, et al. Foley catheter versus vaginal prostaglandin E2 gel for induction of labour at term (PROBAAT trial): an open-label, randomised controlled trial. Lancet 2011; 378(9809):2095-2103.

(8) Jozwiak M, Dodd JM. Methods of term labour induction for women with a previous caesarean section. Cochrane Database Syst Rev 2013;3:CD009792. 
(9) Sciscione AC, Bedder CL, Hoffman MK, Ruhstaller K, Shlossman PA. The timing of adverse events with Foley catheter preinduction cervical ripening; implications for outpatient use. Am J Perinatol 2014 Oct;31(9):781-786.

(10) Prager M, Eneroth-Grimfors E, Edlund M, Marions L. A randomised controlled trial of intravaginal dinoprostone, intravaginal misoprostol and transcervical balloon catheter for labour induction. BJOG 2008 Oct;115(11):1443-1450.

(11) Mackeen AD, Walker L, Ruhstaller K, Schuster M, Sciscione A. Foley Catheter vs Prostaglandin as Ripening Agent in Pregnant Women With Premature Rupture of Membranes. J Am Osteopath Assoc 2014 Sep; 114(9):686-692.

(12) Cabrera IB, Quinones JN, Durie D, Rust J, Smulian JC, Scorza WE. Use of intracervical balloons and chorioamnionitis in term premature rupture of membranes. J Matern Fetal Neonatal Med 2016 Mar; 29(6):967-971.

(13) Kruit H, Tihtonen K, Raudaskoski T, Ulander VM, Aitokallio-Tallberg A, Heikinheimo O, et al. Foley Catheter or Oral Misoprostol for Induction of Labor in Women with Term Premature Rupture of Membranes: A Randomized Multicenter Trial. Am J Perinatol 2016 Jul; 33(9):866872.

(14) Amorosa JMH, Stone J, Factor SH, Booker W, Newland M, Bianco A. A randomized trial of Foley Bulb for Labor Induction in Premature Rupture of Membranes in Nulliparas (FLIP). American Journal of Obstetrics and Gynecology 2017 September 2017; 217(3):360.e1-360.e7.

(15) Mackeen AD, Durie DE, Lin M, Huls CK, Qureshey E, Paglia MJ, et al. Foley Plus Oxytocin Compared With Oxytocin for Induction After Membrane Rupture: A Randomized Controlled Trial. Obstet Gynecol 2018 Jan; 131(1):4-11.

(16) BISHOP EH. Pelvic Scoring for Elective Induction. Obstet Gynecol 1964 Aug; 24:266-268.

(17) American College of Obstetricians and Gynecologists (College), Society for Maternal-Fetal Medicine, Caughey AB, Cahill AG, Guise JM, Rouse DJ. Safe prevention of the primary cesarean delivery. Am J Obstet Gynecol 2014 Mar; 210(3):179-193. 
(18) Siddiqui S, Zuberi NF, Zafar A, Qureshi RN. Increased risk of cervical canal infections with intracervical Foley catheter. J Coll Physicians Surg Pak 2003; 13(3):146-149.

(19) Ekele BA, Isah AY. Cervical ripening: how long can the Foley catheter safely remain in the cervical canal? Afr J Reprod Health 2002;6(3):98-102.

(20) Jozwiak M, Bloemenkamp KW, Kelly AJ, Mol BW, Irion O, Boulvain M. Mechanical methods for induction of labour. Cochrane Database Syst Rev 2012; 3:CD001233.

(21) Jozwiak M, van de Lest HA, Burger NB, Dijksterhuis MG, De Leeuw JW. Cervical ripening with Foley catheter for induction of labor after cesarean section: a cohort study. Acta Obstet Gynecol Scand 2014; 93(3):296-301.

(22) McMaster K, Sanchez-Ramos L, Kaunitz AM. Evaluation of a Transcervical Foley Catheter as a Source of Infection: A Systematic Review and Meta-analysis. Obstet Gynecol 2015; 126(3):539-551.

(23) Korst LM, Fridman M, Friedlich PS, et al. Hospital rates of maternal and neonatal infection in a low-risk population. Matern Child Health J 2005; 9(3):307-316.

(24) Wolff K, Swahn ML, Westgren M. Balloon catheter for induction of labor in nulliparous women with prelabor rupture of the membranes at term. A preliminary report. Gynecol Obstet Invest 1998; 46(1):1-4.

(25) Kawakita T, Reddy UM, Iqbal SN, et al. Duration of Oxytocin and Rupture of the Membranes Before Diagnosing a Failed Induction of Labor. Obstet Gynecol 2016; 128(2):373380.

(26) Grobman WA, Bailit J, Lai Y, et al. Defining failed induction of labor. Am J Obstet Gynecol 2018; 218(1):122.e1-122.e8.

(27) Korst LM, Fridman M, Friedlich PS, et al. Hospital rates of maternal and neonatal infection in a low-risk population. Matern Child Health J 2005;9(3):307-316. 
(28) Stoll BJ, Hansen NI, Sanchez PJ, et al. Early onset neonatal sepsis: the burden of group B Streptococcal and E. coli disease continues. Pediatrics 2011; 127(5):817-826.

(29) Shane AL, Stoll BJ. Neonatal sepsis: progress towards improved outcomes. J Infect 2014; 68(Suppl 1):S24-32. 


\section{TABLES}

Table 1. The characteristics of the study population $(n=1923)$

\begin{tabular}{|c|c|c|c|c|c|}
\hline & \multicolumn{2}{|c|}{ PROM } & \multicolumn{2}{|c|}{ non-PROM } & \multirow{2}{*}{ p-value } \\
\hline & $\mathbf{n}$ & $\%$ & $\mathbf{n}$ & $\%$ & \\
\hline $\mathrm{N}$ & 641 & 33.3 & 1282 & 66.7 & \\
\hline Maternal age $\geq 37$ years & 111 & 17.3 & 218 & 17.0 & 0.86 \\
\hline Nulliparous & 429 & 66.9 & 663 & 51.7 & $<0.001$ \\
\hline Maternal height $<164 \mathrm{~cm}^{1}$ & 257 & 40.2 & 466 & 36.3 & 0.10 \\
\hline Late-term & 129 & 20.1 & 628 & 49.0 & $<0.001$ \\
\hline Post-term & 136 & 21.2 & 856 & 66.8 & $<0.001$ \\
\hline IVF & 28 & 4.4 & 69 & 5.4 & 0.34 \\
\hline Smoking & 49 & 7.6 & 139 & 10.8 & 0.03 \\
\hline $\mathrm{BMI} \geq 30 \mathrm{~kg} / \mathrm{m}^{2}$ & 81 & 12.7 & 264 & 20.6 & $<0.001$ \\
\hline Gestational diabetes $^{3}$ & 126 & 20.1 & 419 & 32.7 & $<0.001$ \\
\hline Previous cesarean section & 110 & 17.2 & 166 & 12.9 & 0.01 \\
\hline GBS colonization ${ }^{4}$ & 131 & 21.3 & 310 & 24.3 & 0.15 \\
\hline
\end{tabular}

${ }^{1}$ Missing values $n=2$ (case).

${ }^{2}$ missing values $\mathrm{n}=1$ (case) and $\mathrm{n}=1$ (control).

${ }^{3}$ missing values $n=15$ (case).

${ }^{4}$ missing values $n=26$ (case) and $n=4$ (controls).

PROM, pre-labor rupture of membranes; IVF, in-vitro fertilization; BMI, body mass index; GBS, Group B Streptococcus. 


\begin{tabular}{|c|c|c|c|c|c|}
\hline & $\begin{array}{l}\text { PRON } \\
(n=64\end{array}$ & & $\begin{array}{l}\text { non- } \\
(\mathrm{n}=1)\end{array}$ & & p-value \\
\hline & $\bar{n}$ & $\%$ & $\mathbf{n}$ & $\%$ & \\
\hline Epidural/spinal analgesia & 520 & 81.1 & 1028 & 80.2 & 0.63 \\
\hline Oxytocin for labor induction & 311 & 57.2 & 494 & 50.9 & 0.02 \\
\hline Oxytocin augmentation & 544 & 84.9 & 970 & 75.7 & $<0.001$ \\
\hline Operative vaginal delivery & 77 & 12.0 & 151 & 11.8 & 0.88 \\
\hline Cesarean section & 152 & 23.7 & 298 & 23.7 & 0.82 \\
\hline Failure to progress ${ }^{1}$ & 100 & 15.6 & 137 & 10.7 & 0.002 \\
\hline Fetal distress & 38 & 5.9 & 120 & 9.4 & 0.010 \\
\hline Intrapartum infection & 4 & 0.6 & 26 & 2.0 & 0.02 \\
\hline Other indication ${ }^{2}$ & 10 & 1.6 & 15 & 1.2 & 0.48 \\
\hline Post-partum hemorrhage $\geq 1000 \mathrm{ml}$ & 99 & 15.4 & 190 & 14.8 & 0.72 \\
\hline $\begin{array}{l}\text { Rupture of membranes to delivery interval } \geq \\
24 \mathrm{~h}\end{array}$ & 584 & 91,1 & 162 & 12,6 & $<0.001$ \\
\hline Duration of labor (h; median [range]) & 7.7 & $0.9-36.5$ & 6.7 & $0.4-31.3$ & $<0.001$ \\
\hline Induction to delivery interval (median; range) & 17.4 & 2.6-75.7 & 26.2 & $3.2-163.7$ & $<0.001$ \\
\hline Induction to delivery interval $\geq 24 \mathrm{~h}$ & 184 & 28.7 & 691 & 53.1 & $<0.001$ \\
\hline Induction to delivery interval $\geq 48 \mathrm{~h}$ & 17 & 2.7 & 192 & 15.0 & $<0.001$ \\
\hline Birthweight (g; mean $[\mathrm{SD}])$ & 3430 & 440 & 3560 & 500 & $<0.001$ \\
\hline 5 min Apgar score $<7$ & 22 & 3.4 & 43 & 3.4 & 0.97 \\
\hline Umbilical artery $\mathrm{pH} \leq 7.05$ & 12 & 1.9 & 20 & 1.6 & 0.66 \\
\hline Umbilical artery $\mathrm{BE} \leq 12$ & 9 & 1.4 & 22 & 1.8 & 0.57 \\
\hline NICU & 15 & 2.3 & 93 & 7.3 & $<0.001$ \\
\hline
\end{tabular}

${ }^{1}$ Failed vacuum delivery: PROM group $\mathrm{n}=3$; non-PROM group $\mathrm{n}=9$.

2PROM group: fetal malpresentation $(n=2)$, maternal request $(n=1)$, placental abruption $(n=3)$, umbilical cord prolapse $(\mathrm{n}=4)$; Non-PROM: fetal malpresentation $(\mathrm{n}=2)$, maternal request $(\mathrm{n}=3)$, placental abruption $(\mathrm{n}=2)$, umbilical cord prolapse $(\mathrm{n}=1)$, preeclampsia $(\mathrm{n}=7)$.

PROM, pre-labor rupture of membranes; BE, blood gas values; NICU, neonatal intensive care unit. 
Table 3. Infectious morbidity

\begin{tabular}{|c|c|c|c|c|c|}
\hline & \multicolumn{2}{|c|}{$\operatorname{PROM}(n=641)$} & \multicolumn{2}{|c|}{ Non-PROM (n=1282) } & \multirow[t]{2}{*}{ p-value } \\
\hline & $\mathbf{n}$ & $\%$ & $\mathbf{n}$ & $\%$ & \\
\hline Maternal intrapartum infection & 24 & 3.7 & 99 & 7.7 & 0.001 \\
\hline Blood culture positive sepsis ${ }^{1}$ & & & 6 & 0.5 & \\
\hline Maternal post-partum infection & 13 & 2.0 & 36 & 2.8 & 0.31 \\
\hline Endometritis & 5 & 0.8 & 20 & 1.6 & 0.16 \\
\hline Cesarean section wound infection & 2 & 0.3 & 9 & 0.7 & 0.36 \\
\hline Abdominal/pelvic infection & 1 & 0.2 & 4 & 0.3 & 0.67 \\
\hline Other ${ }^{2}$ & 3 & 0.5 & 3 & 0.2 & 0.41 \\
\hline Blood culture positive sepsis ${ }^{3}$ & 2 & 0.3 & & & \\
\hline Neonatal infection & 11 & 1.7 & 49 & 3.8 & 0.01 \\
\hline Blood culture positive sepsis & 0 & & 1 & 0.001 & \\
\hline Clinical sepsis & 1 & 0.2 & 8 & 0.6 & 0.51 \\
\hline Suspected sepsis & 9 & 1.4 & 35 & 2.7 & 0.07 \\
\hline Other suspected infection & 1 & 0.2 & 5 & 0.4 & \\
\hline
\end{tabular}

${ }^{1}$ Stafylococcus epidermoides n=1, Stafylococcus anginosus n=1, Group B Streptococcus (GBS) n=1, Stafylococcus aureus $\mathrm{n}=1$, Grannulicatella elegans $\mathrm{n}=1$, Enterococcus fecalis $\mathrm{n}=1$

${ }^{2}$ PROM group: episiotomy wound infection $(\mathrm{n}=1)$, urinary tract infection $(\mathrm{n}=2)$; Controls: episiotomy wound infection $(\mathrm{n}=1)$, urinary tract infection $(\mathrm{n}=1)$, pneumonia $(\mathrm{n}=1)$

${ }^{3}$ Entorococcus faecalis $\mathrm{n}=1$, Escherichia coli with Siprolla $\mathrm{n}=1$

PROM, pre-labor rupture of membranes. 
Table 4A. Unadjusted and adjusted risk factors for maternal intrapartum infection

\begin{tabular}{lllllll}
\hline & \multicolumn{2}{l}{ Unadjusted intrapartum infection } & \multicolumn{2}{l}{ Adjusted intrapartum infection } \\
& OR & CI (95 \%) & p-value & OR & CI (95 \%) & p-value \\
\hline Nulliparity & 2.4 & $1.6-3.6$ & $<0.001$ & 3.3 & $1.6-6.5$ & 0.001 \\
Maternal age $\geq 37$ & 0.6 & $0.3-1.0$ & 0.047 & 0.7 & $0.4-1.3$ & 0.28 \\
Height $<160 \mathrm{~cm}$ & 1.1 & $0.7-1.5$ & 0.743 & 1.1 & $0.7-1.6$ & 0.70 \\
PROM & 0.5 & $0.3-0.7$ & 0.001 & 0.6 & $0.3-1.1$ & 0.08 \\
IVF & 1.1 & $0.5-2.5$ & 0.735 & 1.3 & $0.6-3.0$ & 0.54 \\
Smoking & 0.9 & $0.5-1.7$ & 0.748 & 0.8 & $0.4-1.5$ & 0.44 \\
BMI $\geq 30$ & 1.5 & $1.0-2.4$ & 0.049 & 1.6 & $1.0-2.6$ & 0.06 \\
Previous CS & 1.1 & $0.6-1.8$ & 0.722 & 2.8 & $1.2-6.4$ & 0.02 \\
Bishop $\leq 3$ & 2.0 & $1.2-3.1$ & 0.004 & 1.3. & $0.7-2.4$ & 0.40 \\
Gestational age $\geq 41$ weeks & 2.1 & $1.5-3.1$ & $<0.001$ & 1.9 & $1.2-3.0$ & 0.003 \\
Need of oxytocin for IOL & 1.1 & $0.7-1.5$ & 0.787 & 1.0 & $0.6-1.5$ & 0.91 \\
Epidural/spinal analgesia & 2.1 & $1.2-3.8$ & 0.010 & 1.3 & $0.7-2.7$ & 0.42 \\
Gestational diabetes & 1.2 & $0.8-1.7$ & 0.425 & 1.3 & $0.8-2.0$ & 0.30 \\
GBS colonization & 0.5 & $0.3-0.9$ & 0.013 & 0.5 & $0.3-0.8$ & 0.008 \\
Induction to delivery interval $\geq 48 \mathrm{~h}$ & 3.2 & $2.1-5.0$ & $<0.001$ & 2.0 & $1.2-3.3$ & 0.005 \\
\hline
\end{tabular}

PROM, pre-labor rupture of membranes; IVF, in-vitro fertilization; BMI, body mass index; IOL, induction of labor; GBS, Group B Streptococcus. 
Table 4B. Unadjusted and adjusted risk factors for neonatal infection

\begin{tabular}{lllllll}
\hline & \multicolumn{2}{l}{ Unadjusted neonatal infection } & \multicolumn{3}{c}{ Adjusted neonatal infection } \\
\hline & OR & CI (95 \%) & p-value & OR & CI (95 \%) & p-value \\
Nulliparity & 3.9 & $2.2-6.9$ & $<0.001$ & 3.3 & $1.4-8.0$ & 0.01 \\
Maternal age $\geq 37$ & 0.8 & $0.4-1.5$ & 0.543 & 1.1 & $0.5-2.3$ & 0.38 \\
Height $<160 \mathrm{~cm}$ & 0.7 & $0.4-1.2$ & 0.172 & 0.8 & $0.4-1.3$ & 0.15 \\
PROM & 0.5 & $0.3-0.8$ & 0.007 & 0.7 & $0.3-1.7$ & 0.46 \\
IVF & 1.8 & $0.8-4.1$ & 0.140 & 1.6 & $0.6-4.2$ & 0.31 \\
Smoking & 1.8 & $1.0-3.3$ & 0.058 & 1.6 & $0.7-3.2$ & 0.25 \\
BMI $\geq 30$ & 1.0 & $0.6-1.8$ & 0.936 & 0.9 & $0.4-1.0$ & 0.73 \\
Previous CS & 0.5 & $0.2-1.2$ & 0.124 & 0.5 & $0.1-2.6$ & 0.40 \\
Bishop $\leq 3$ & 1.7 & $1.0-2.9$ & 0.055 & 1.2 & $0.6-2.7$ & 0.61 \\
Gestational age $\geq 41$ weeks & 2.5 & $1.6-3.9$ & $<0.001$ & 1.9 & $1.1--3.4$ & 0.03 \\
Need of oxytocin for IOL & 1.2 & $0.7-2.0$ & 0.479 & 1.1 & $0.7-1.9$ & 0.69 \\
Epidural/spinal analgesia & 1.4 & $0.8-2.7$ & 0.256 & 1.1 & $0.5-2.6$ & 0.77 \\
Gestational diabetes & 1.1 & $0.7-1.9$ & 0.587 & 1.2 & $0.7-2.2$ & 0.52 \\
Maternal GBS colonization & 0.5 & $0.3-1.0$ & 0.039 & 0.4 & $0.2-0.9$ & 0.03 \\
Induction to delivery interval $\geq 48 \mathrm{~h}$ & 4.5 & $2.8-7.3$ & $<0.001$ & 3.4 & $1.9-6.0$ & $<0.001$ \\
\hline
\end{tabular}

PROM, pre-labor rupture of membranes; IVF, in-vitro fertilization; BMI, body mass index; IOL, induction of labor; GBS, Group B Streptococcus. 